\title{
ADSORPSI KESADAHAN (Ca) MENGGUNAKAN ADSORBEN BERBASIS SEKAM PADI
}

\author{
A.S. Dwi Saptati Nur Hidayati*, Juliananda, Bambang Ismuyanto \\ Program Studi Teknik Kimia, Fakultas Teknik, Universitas Brawijaya \\ Jl. Mayjen Haryono 167 Malang \\ *Email: say2as@ub.ac.id
}

\begin{abstract}
Abstrak
Penelitian ini bertujuan untuk mengkaji pemanfaatan limbah sekam padi sebagai bahan baku adsorben tanpa proses karbonisasi. Karakterisasi adsorben berbasis sekam padi diuji menggunakan FTIR. Eksperimen dilakukan dengan beberapa variasi parameter, yaitu waktuadsorpsi(30-180 menit) dan konsentrasi Ca awal $(164,8-329,6) \mathrm{mg} / \mathrm{L}$. Selanjutnya dilakukan kajian awal untuk evaluasi kelayakan aplikasi pemanfaatan adsorben yaitu melalui uji adsorpsi isotermis menggunakan persamaan Langmuir dan Freundlich. Hasil yang diperoleh menunjukkan bahwa penurunan kesadahan (Ca) maksimum sebesar 35.98\% yang terjadi pada konsentrasi $\mathrm{Na}_{2} \mathrm{SO}_{4} 1 \mathrm{M}$ dengan waktu adsorpsi 150 menit. Proses adsorpsi kesadahan $(\mathrm{Ca})$ oleh adsorben sekam padi memenuhi pola isoterm Langmuir dengan kapasitas adsorpsi maksimum adsorben berbasis sekam padi terhadap penyerapan kesadahan $(\mathrm{Ca})$ sebesar $18,52 \mathrm{mg} / \mathrm{gr}$.
\end{abstract}

Kata kunci: adsorben, kesadahan, Langmuir, sekam padi

\begin{abstract}
This study reports adsorption of hardness $(\mathrm{Ca})$ onto rice husk-basedadsorben. Characterization of rice husk-based adsorbent was identified by FTIR. Experiments were carried aout with several parametersvariations such as adsorption time (30-180 minutes) and the initial hardness (Ca) concentration (164.8 to 329.6$) \mathrm{mg} / \mathrm{L}$. Furthermore, initial study to evaluate the feasibility of adsorbent application was doneusing Langmuir and Freundlichtest. The results showed that hardness (Ca)removalup to $35.98 \%$ at a concentration of $\mathrm{Na}_{2} \mathrm{SO}_{4} 1 \mathrm{M}$ and adsorption time 150 minutes. The adsorption data obtained data were fitted well to Langmuir isotherm model with adsorption capacity of rice husk-based adsorbent was found to be $18.52 \mathrm{mg} / \mathrm{g}$.
\end{abstract}

Keywords:adsorbent, hardness, Langmuir, Rice Husk

\section{Pendahuluan}

Kalsium dan Magnesium merupakan bentuk kontaminan air yang berpengaruh terhadap kesadahan. Kedua ion tersebut mudah larut di dalam perairan sehingga dapat menyebabkan perairan menjadi sadah [1]. Kesadahan dapat menyebabkan beberapa permasalahan, diantaranya adalah timbulnya kerak pada berbagai peralatan (boiler, mesin cuci, perpipaan, dll), dapat mengurangi daya kerja sabun, rambut dan kulit menjadi kasar [13]. Bagi kesehatan, kesadahan dapat menyebabkan penyakit ginjal dan kanker [12].

Berdasarkan beberapa permasalahan tersebut di atas, maka perlu adanya upaya untuk menurunkan kesadahan dalam perairan. Beberapa metode telah dilakukan untuk menghilangkan kesadahan dalam perairan, diantaranya adalah penukar ion [10], penambahan bahan kimia [15], penggunaan zeolite [5] dan proses elektrodeionisasi [8]. Berbagai metode tersebut hingga saat ini masih terus dikembangkan khususnya penggunaan bahan baku yang ramah lingkungan. Bahan baku yang utamanya banyak menjadi sasaran peneliti adalah limbah pertanian dan perkebunan. Berbagai bahan baku yang telah digunakan sebagai adsorben untuk menurunkan kesadahan diantaranya adalah limbah buah melon [14], tempurung kelapa [13] dan bagasse [15].

Sekam padi menjadi salah alternatif bahan baku adsorben yang potensial. Beberapa keunggulan yang dimiliki oleh sekam padi sebagai kandidat adsorben diantaranya adalah tidak larut dalam air, memiliki stabilitas kimia yang baik dan kekuatan struktur yang baik karena memiliki kandungan silika yang tinggi [9]. Disamping itu sekam padi merupakan bahan baku yang murah dan mudah diperoleh karena ketersediaannya melimpah. Berdasarkan data Badan Pusat Statistik disebutkan bahwa produksi Padi di Indonesia tahun 2014sebanyak 70,85 juta ton gabah kering giling (GKG) dan pada tahun 2015 diperkirakan mencapai 75,55 juta ton per tahun. Berdasarkan data ini dapat diketahui bahwa jumlah sekam padi yang dihasilkan 
adalah sekitar $10 \%$ dari produksi padiyaitu7,555 ton per tahunnya. Pemanfaatan sekam padi menjadi adsorben dapat mengurangi pencemaran lingkungan akibat pembakaran sekam padi [7].

Pada umumnya sekam padi disintesis terlebih dahulu menjadi karbon sebelum dijadikan adsorben, namun pada penelitian ini pembuatan adsorben berbasis sekam padi dilakukan tanpa proses karbonisasi. Pembuatan adsorben dengan melakukan penambahan sodium sulfat. Selanjutnya akan dilakukan kajian awal untuk evaluasi kelayakan aplikasi pemanfaatan adsorben hasil penelitian terkait penentuan kapasitas adsorpsi menggunakan pola isotem Langmuir dan Freundlich.

\section{Teori}

Sekam padi mengandung selulosa, hemiselulosa dan lignin saling berikatan satu sama lainnya membentuk suatu struktur matrik yang sangat stabil. Lapisan dalam sekam padi sangat halus dan mengandung lilin maupun lemak alami. Disamping itu adanya pengotor pada lapisan dalam sekam padi dapat berpengaruh terhadap sifat/kemampuan adsorpsi sekam padi baik secara kimia atau fisik. Apabila pengotor yang terdapat pada sekam padi dihilangkan, dapat meningkatkan kekasaran pada permukaan sehingga dapat membuka gugus hydroxyl pada permukaan sekam padi [3].

Adsorpsi merupakan suatu fenomena yang berkaitan erat dengan permukaan yang melibatkan interaksi antara molekul-molekul cairan atau gas dengan molekul padatan akibat adanya gaya tarik atom atau molekul. Proses adsorpsi dapat terjadi karena adanya gaya tarik atom atau molekul pada permukaan padatan yang tidak seimbang. Fluida mengalir ke partikel, terjadi difusi solute dari fluida ke permukaan terluar partikel kemudian solute terdifusi ke dalam pori dan menempel di permukaanpori. Akibatnya, solute tersebut dapat teradsorbsi di permukaan [4].

Karakteristik yang paling pentingdari material adsorben adalah struktur pori. Jumlah total pori, bentuk, dan ukurannyamenentukankapasitas adsorpsi dan laju adsorpsi. Banyak adsorben padat memiliki struktur kompleks yang terdiri dari pori ukurandan bentuk bervariasi. Porositas diklasifikasikanmenjadi 3 jenis yaitu mikropori, mesopori, dan makropori. Diameter mikropori sebesar 8-100 A, mesopori sebesar 100 - $500 \AA$, dan makropori sebesar 500 $20000 \AA$ A [11].

Eksperimen adsorpsi isothermis merupakan salah satu cara yang berguna untuk menggambarkan kapasitas adsorpsi untuk melakukan evaluasi awal untuk kelayakan aplikasi, pemilihan adsorben dan perhitungan awal dosis penggunaan adsorben. Lebih jauh, adsorpsi isothermis dapat memperkirakan kinetika/model untuk analisis dan desain proses adsorpsi [7]. Langmuir dan Freundlich merupakan pendekatan yang paling sering digunakan untuk menggambarkan data adsorpsi dari suatu larutan.

\section{Metodologi Penelitian \\ Adsorben}

Bahan baku yang digunakan dalam penelitian ini adalah sekam padi yang diperoleh dari daerah Malang Jawa Timur. Hasil analisa komposisi awal sekam padi ditunjukkan pada Tabel 1, sedangkan hasil uji FTIR ditunjukkan pada Gambar 1.

Sekam padi dihancurkan hingga diperoleh ukuran 50-80 mesh, kemudian dicuci menggunakan deionized water untuk menghilangkan pengotor, dan dikeringkan dalam oven pada suhu $105^{\circ} \mathrm{C}$. Sekam padi yang telah dikeringkan kemudian ditambahkan sodium sulfat dengan variasi konsentrasi $(0.5,1$ dan2 M), diaduk dan direndam selama 1 jam. Selanjutnya dilakukan penyaringan, pencucian dan pengeringan.

Tabel 1. Komposisi sekam padi awal

\begin{tabular}{|c|c|c|}
\hline Komponen & Wt(\%) & At(\%) \\
\hline $\mathbf{C}$ & 45.89 & 54.99 \\
\hline $\mathbf{O}$ & 45.18 & 40.64 \\
\hline $\mathbf{M g}$ & 0.63 & 0.37 \\
\hline $\mathbf{S i}$ & 5.69 & 2.92 \\
\hline $\mathbf{P}$ & 1.18 & 0.55 \\
\hline $\mathbf{S}$ & 0.18 & 0.08 \\
\hline $\mathbf{K}$ & 1.24 & 0.46 \\
\hline
\end{tabular}

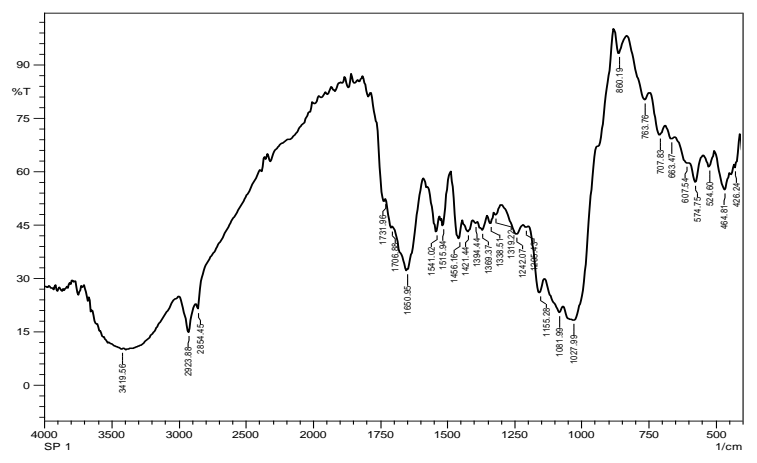

\section{Gambar 1. Hasil uji FTIR Sekam Padi}

\section{Adsorbat}

Air sadah sintetis yang digunakan pada penelitian ini dilakukan dengan cara melarutkan 1,4 gram $\mathrm{CaCl}_{2}$ ke dalam 1 liter deionizedwater sehingga akan diperoleh larutan dengan konsentrasi Ca 329,6mg/L. Selanjutnya, larutan ini akan digunakan sebagai larutan induk untuk variasi konsentrasi $\mathrm{Ca}$ awal.

\section{Adsorpsi}

Uji coba adsorben untuk adsorpsi kesadahan (Ca) dilakukan pada rotary shakerdengan kecepatan 4.000 rpm. Analisa kandungan kesadahan (Ca) dilakukan pada sampel air sebelum dan sesudah proses adsorpsi untuk mengetahui jumlah penurunan kesadahan (Ca) akibat adanya adsorben. Parameter 
yang divariasikan meliputi waktu adsorpsi (30-180 menit) dan konsentrasi kesadahan (Ca) awal (164,8329,6) ppm. Pengujian pola isoterm adsorpsi yang sesuai untuk proses penyerapan kesadahan $(\mathrm{Ca})$ oleh adsorben dilakukan dengan perhitungan menggunakan persamaan Langmuir dan Freundlich.

\section{Hasil}

Pada penelitian ini, sekam padi ditambahkan $\mathrm{Na}_{2} \mathrm{SO}_{4}$ untuk mendekomposisi garam-garam mineral yang terdapat pada sekam padi sehingga membentuk gugus fungsi yang dapat mengikat $\mathrm{Ca}$. Kemudian dilakukan pemanasan yang bertujuan untuk menghilangkan kandungan air dalam adsorben. Selain itu pemanasan pada suhu $105^{\circ} \mathrm{C}$ dapat meningkatkan porositas dinding sel adsorben sehingga luas permukaan adsorpsi semakin besar. Jika luas permukaan adsorpsi adsorben semakin besar, maka kemampuan adsorben untuk menyerap adsorbat juga akan semakin besar. Suhu pemanasan harus dijaga konstan, karena apabila melebihi $105^{\circ} \mathrm{C}$ dapat mengakibatkan kerusakan struktur sel adsorben, penyusutan volume dan penutupan poripori adsorben sehingga akan mengurangi kemampuan adsorpsi adsorben.



Gambar 2. Hubungan konsentrasi Ca dengan waktu adsorpsi (konsentrasi Ca awal=164,8 mg/L)

Adsorben yang dihasilkan pada penelitian ini kemudian diuji kemampuan adsorpsi terhadap kesadahan $(\mathrm{Ca})$ dengan variasi konsentrasi awal dan waktu adsorpsi. Penurunan konsentrasi kesadahan (Ca) selama proses adsorpsi ditunjukkan pada Gambar 2.

Berdasarkan Gambar 2, profil penurunan konsentrasi Ca hampir sama pada konsentrasi $\mathrm{Na}_{2} \mathrm{SO}_{4}$ 0,5 M, $1 \mathrm{M}$ dan 2M. Jika ditinjau dari hubungan antara penurunan konsentrasi $\mathrm{Ca}$ dengan waktu adsorpsi, terlihat bahwa pada 30 menit awal proses adsorpsi konsentrasi $\mathrm{Ca}$ menurun secara signifikan, sedangkan pada waktu 120 menit konsentrasi Ca setelah proses adsorpsi cenderung konstan. Hal ini diduga karena pada tahap awal, masih banyak ruang kosong pada adsorben yang dapat diisi oleh molekul Ca. Semakin lama adsorben kontak dengan larutan yang mengandung $\mathrm{Ca}$, maka semakin banyak pula molekul Ca yang menempati ruang kosong pada adsorben. Akibatnya terjadi daya tarik antara fasa padat (adsorben) dan fasa cair (larutan $\mathrm{Ca}$ ) menyebabkan molekul Ca yang masih bebas di dalam larutan akan sulit untuk menempati sisa ruang kosong pada adsorben. Oleh karena itu pada menit ke 120, konsentrasi Ca cenderung konstan.

Melalui hasil analisa ini dapat diketahui pula profil efisiensi penurunan konsentrasiCa (\%Removal) akibat adanya adsorben yang ditunjukkan pada Gambar 3.



Gambar 3. Pengaruh waktu adsorpsi dan konsentrasi $\mathrm{Na}_{2} \mathrm{SO}_{4}$ terhadap $(\%)$ Removal Ca $($ konsentrasi Ca awal $=164,8 \mathrm{mg} / \mathrm{L})$

Berdasarkan gambar 3, terlihat bahwa penurunan konsentrasi $\mathrm{Ca}$ tertinggi untuk konsentrasi $\mathrm{Na}_{2} \mathrm{SO}_{4} 0.5$ M,1 $\mathrm{M}$ dan $2 \mathrm{M}$ masing-masing sebesar 26,21\%, $35,98 \%$ dan $16,26 \%$.

Karakterisasi adsorben dengan uji FTIR juga telah dilakukan. Uji FTIR berfungsi untuk mengidentifikasi gugus fungsi yang terdapat pada adsorben berbasis sekam padi yang kemungkinan berperan pada proses adsorpsi kesadahan $(\mathrm{Ca})$. Hasil uji FTIR adsorben berbasis sekam padi yang dihasilkan pada penelitian ini ditunjukkan pada Gambar 4. Hasil pengujian FTIR menunjukkan bahwa pada adsorben yang dihasilkan dengan penambahan $\mathrm{Na}_{2} \mathrm{SO}_{4} \quad 0,5 \mathrm{M} ; 1 \mathrm{M}$ dan $2 \mathrm{M}$ memiliki profil yang hampir sama. Gugus fungsi yang terdapat pada adsorben diantaranya adalah gugus $\mathrm{O}-\mathrm{H}$ (panjang gelombang sekitar $3400 \mathrm{~cm}^{-1}$ ), amine $\mathrm{N}-\mathrm{H}$ (panjang gelombang sekitar $1600 \mathrm{~cm}^{-1}$ ), alkoxy $\mathrm{C}-\mathrm{O}$ (panjang gelombang sekitar $1045 \mathrm{~cm}^{-1}$ ) dan nitro $\mathrm{N}-\mathrm{O}$ (panjang gelombang sekitar $1400 \mathrm{~cm}^{-1}$ ). 

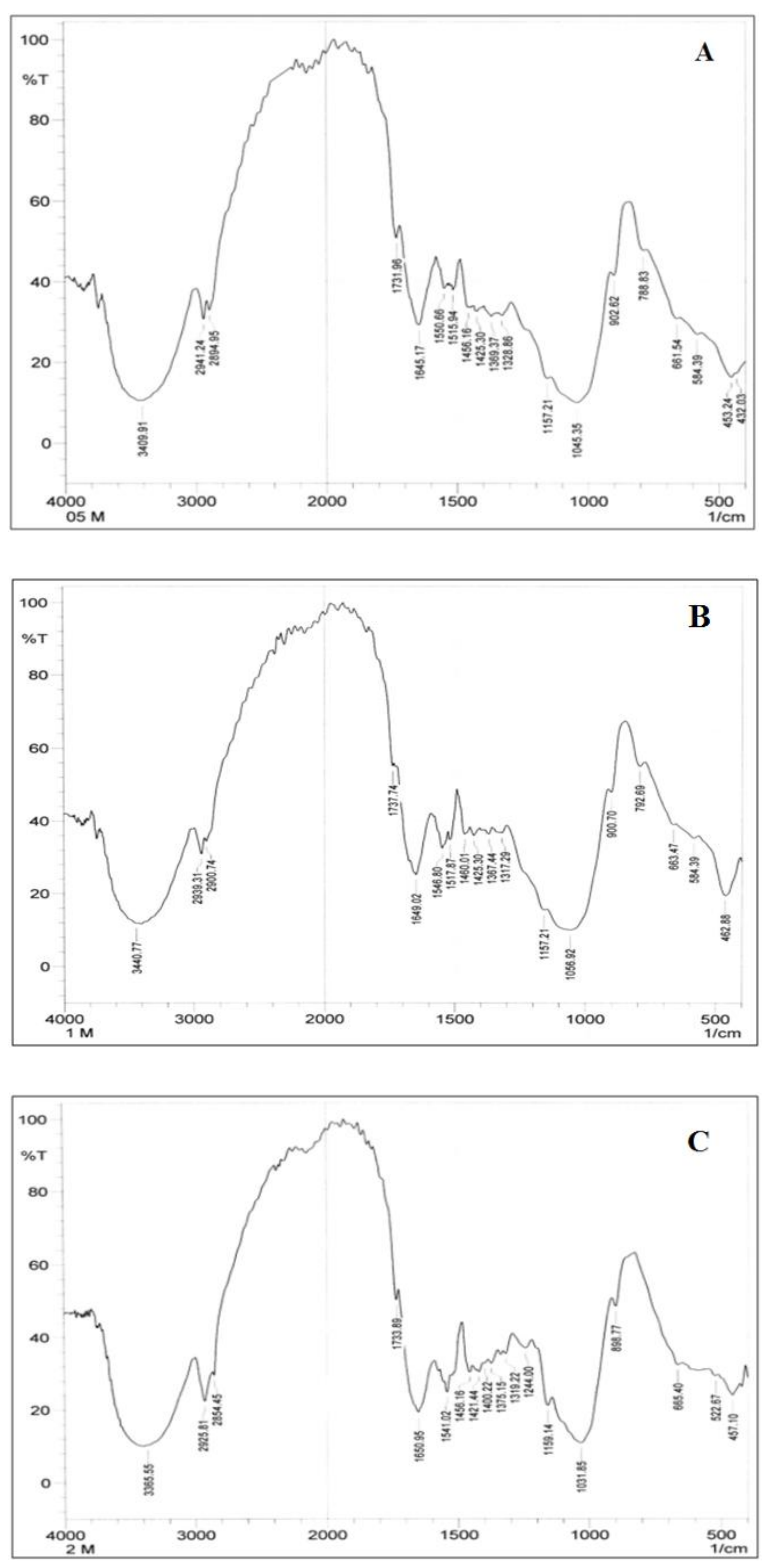

Gambar 4. Hasil uji FTIR adsorben berbasis sekam padi (a) $\mathrm{Na}_{2} \mathrm{SO}_{4}$ 0,5M (b) $\mathrm{Na}_{2} \mathrm{SO}_{4} 1 \mathrm{M}$ (c) $\mathrm{Na}_{2} \mathrm{SO}_{4} 2 \mathrm{M}$

Pengujian pola isoterm adsorpsi untuk mengetahui distribusi proses penyerapan $\mathrm{Ca}$ oleh adsorben berbasis sekam padi dilakukan dengan perhitungan menggunakan persamaan Langmuir dan Freundlich. Pola isoterm Langmuir dilakukan menggunakan persamaan (2) berikut.

$$
q_{e}=\frac{Q_{0} b C_{e}}{1+b C_{e}}
$$

dimana $\mathrm{q}_{\mathrm{e}}$ menunjukkan jumlah $\mathrm{Ca}$ yang diadsorpsi $(\mathrm{mg} / \mathrm{g}), \mathrm{Ce}$ adalah konsentrasi $\mathrm{Ca}(\mathrm{mg} / \mathrm{L})$ pada kesetimbangan, Qo dan b merupakan konstanta Langmuir yang masing-masing berkaitan dengan kapasitas dan energi adsorpsi. Untuk memperoleh nilai konstanta Langmuir, maka persamaan (1) dilinearisasi menjadi persamaan (2).

$$
\frac{C_{e}}{q_{e}}=\frac{1}{Q_{0} b}+\frac{C_{e}}{Q_{0}}
$$

Berdasarkan persamaan (2), maka dapat dibuat grafik antara $\mathrm{Ce}$ dan $\mathrm{q}_{\mathrm{e}} / \mathrm{C}_{\mathrm{e}}$ seperti ditunjukkan pada Gambar 5.

Sedangkan pola isoterm Freundlich dilakukan menggunakan persamaan (3).

$$
q_{e}=K_{F} C_{e}^{1 / n}
$$

dimana $K_{F}$ menunjukkan kapasitas adsorpsi dan $n$ mengindikasikan kesesuaian prosess adsorpsi. Untuk memperoleh nilai $\mathrm{K}_{\mathrm{F}}$ dan $\mathrm{n}$, maka persamaan (3) diubah menjadi bentuk linear seperti ditunjukkan pada persamaan (4).

$$
\ln \left(q_{e}\right)=\ln \left(K_{F}\right)+\left(\frac{1}{n}\right) \ln \left(C_{e}\right)
$$

Dari persamaan (4) dapat dibuat plot antara $\ln \left(\mathrm{K}_{\mathrm{F}}\right)$ dan $\ln \left(\mathrm{C}_{\mathrm{e}}\right)$ seperti ditunjukkan pada Gambar 6 , sehingga nilai $K_{F}$ dan $n$ masing-masing dapat diperoleh dari intersep dan slope.

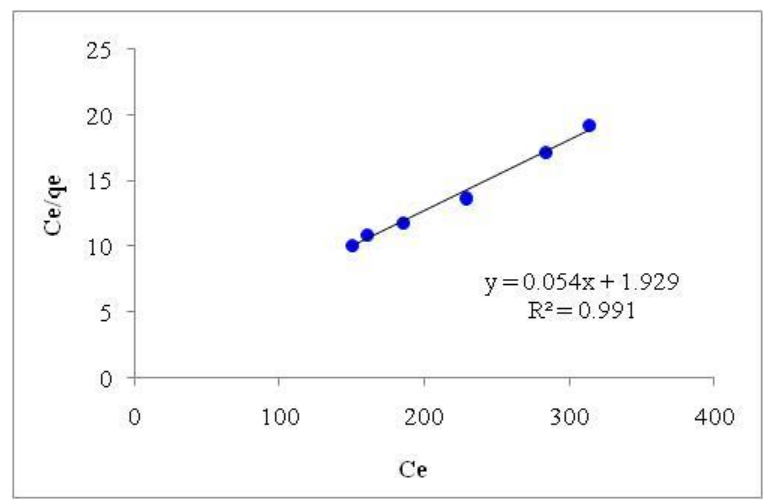

Gambar 5. Grafik pola isotherm Langmuir untuk adsorpsi Ca pada adsorben berbasis sekam padi

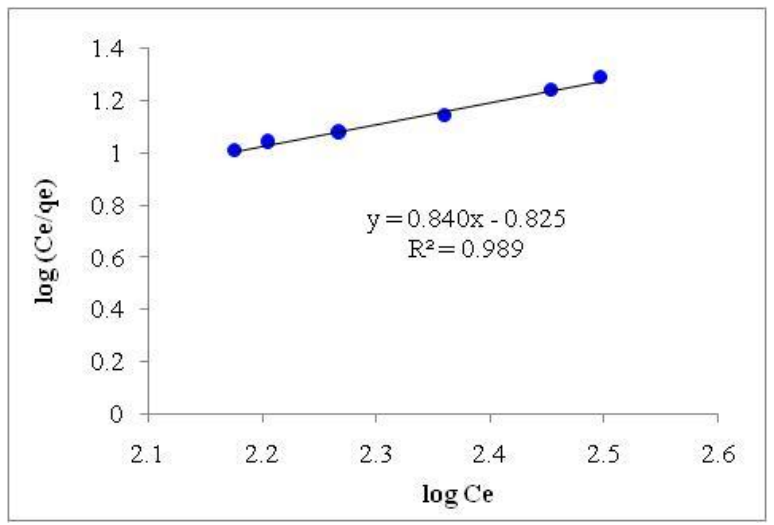

Gambar 6. Grafik pola isotherm Freundlich untuk adsorpsi Ca pada adsorben berbasis sekam padi

Dari Gambar 5 dan 6, maka dapat diperoleh konstanta dan koefisien korelasi pola isoterm Langmuir dan Freundlich seperti disajikan pada Tabel 2 . 
Tabel 2. Konstanta dan koefisien korelasi pola isoterm Langmuir dan Freundlich

\begin{tabular}{|c|c|}
\hline \multicolumn{1}{|c|}{ Parameter } & Nilai \\
\hline Langmuir & \\
$\mathrm{Q}_{0}(\mathrm{mg} / \mathrm{g})$ & 18,52 \\
$\mathrm{~b}(\mathrm{~L} / \mathrm{mg})$ & 0,028 \\
$\mathrm{R}^{2}$ & 0,991 \\
Freundlich & \\
$\mathrm{K}_{\mathrm{F}}$ & 6,61 \\
$\mathrm{n}$ & 1,19 \\
$\mathrm{R}^{2}$ & 0,989 \\
\hline
\end{tabular}

Apabila ditinjau dari nilai $\mathrm{R}^{2}$, maka pola isoterm Langmuir memberikan fitting data eksperimen yang lebih baik dibandingkan dengan Freundlich, dimana $\mathrm{R}^{2}$ Langmuir 0,991 sedangkan $\mathrm{R}^{2}$ Freundlich lebih rendah yaitu sebesar 0,989. Berdasarkan hal ini, maka dapat diduga bahwa distribusi Ca ke dalam adsorben berbasis sekam padi bersifat homogen karena pola isoterm Langmuir membuat asumsi bahwa permukaan adsorben adalah homogen. Kapasitas adsorpsi berdasarkan pola isoterm Langmuir sebesar 18,52 mg/gr.

Berdasarkan Hameed, et al (2008), kesesuaian pola isoterm Langmuir dapat ditentukan melalui konstanta tidak berdimensi $\left(\mathrm{R}_{\mathrm{L}}\right)$ menggunakan persamaan (5) sebagai berikut:

$$
R_{L}=\frac{1}{(1+\mathrm{bC} 0)}
$$

dimana $\mathrm{C}_{0}$ yaitu konsentrasi awal adsorbat tertinggi $(\mathrm{mg} / \mathrm{L})$, dan $\mathrm{b}$ adalah konstanta Langmuir $(\mathrm{L} / \mathrm{mg})$. Nilai $R_{L}$ menunjukkan kesesuaian pola isoterm Langmuir terhadap proses adsorpsi, yaitu sesuai $\left(0<R_{L}<1\right)$, linear $\left(R_{L}=1\right)$ dan tidak sesuai $\left(R_{L}>1\right)[6]$. Pada penelitian ini diperoleh nilai $\mathrm{R}_{\mathrm{L}}$ sebesar 0,098 , hal ini berarti bahwa proses adsorpsi pada adsorben berbasis sekam padi sesuai untuk penurunan $\mathrm{Ca}$.

\section{Kesimpulan}

Dari penelitian ini, penurunan konsentrasi kesadahan (Ca) maksimum sebesar $35.98 \%$ yang terjadi pada konsentrasi $\mathrm{Na}_{2} \mathrm{SO}_{4} 1 \mathrm{M}$ dengan waktu adsorpsi 150 menit. Proses adsorpsi Ca oleh adsorben sekam padi memenuhi pola isoterm adsorpsi Langmuir yang menunjukkan bahwa kapasitas adsorpsi maksimum adsorben sekam padi terhadap penyerapan $\mathrm{Ca}$ adalah sebesar $18,52 \mathrm{mg} / \mathrm{gr}$.

\section{Daftar Pustaka}

[1] Agostinho, L. C. L., Nascimento, L. and Cavalcanti, B. F.,Water Hardness Removal for Industrial Use, Application of the Electrolysis Process, (2012) 1:460.

[2] Badan Pusat Statistik, Produksi Padi, Jagung dan Kedelai, Berita Resmi Statistik, 01 Juli 2015.

[3] B.S. Ndazi, S. Karlsson, J.V. Tesha, C.W. Nyahumwa, Chemical and Physical Modifications of Rice Husks for Use as Composite Panels, Composites: Part A 38 pp.,(2007) 925-935.

[4] Geankoplis, C.J, Transport Processes and
Unit Operations $3^{\text {rd }}$ Edition. New Jersey : PTR Prentice-Hall. Inc (1993).

[5] Goud, Viswanath R., Kumar, B. Lenin, Abhilash, N., Prasad, P. Rajendra and Saradhi, B. Vijaya, Comparision studies on Adsorbants for removal of Hardness from Water by using newly Prepared Zeolite, International Journal of Advances in Pharmacy, Biology and Chemistry, IJAPBC-Vol. 4(2), (2015) AprilJune.

[6] Hameed, B. H., Mahmoud, D. K., \& Ahmad, A. L., Equilibrium modeling and kinetic studies on the adsorption of basic dye by a low-cost adsorbent: Coconut (Cocosnucifera) bunch waste. Journal of Hazardous Materials, 158(1), (2008) 65-72.

[7] Kumar, U., Bandyopadhyay, M, Sorption of cadmium from aqueous solution using pretreated rice husk., Bioresource Technology 97, (2006) 104-109.

[8] L. Fu, J. Wang, Y. Su, Removal of low concentrations of hardness ions from aqueous solutions using electrodeionization process, Sep. Purif. Technol. 68 (2009) 390-396.

[9] Lee, C.K., Low, K.S., Liew, S.C., Choo, C.S., Removal of arsenic (V)from aqueous solution by quaternized rice husk, Environ. Technol. 20, (1999) 971-978.

[10] Manahan, S. E.,Environmental Chemistry. (7th ed)Boca Raton: CRC Press LLC, (2000).

[11] McDOUGALL, G.J., The Physical Nature and Manufacture of Activated Carbon. JurnalS.Afr.Inst.Min. Metal, (1991) 90(4): 109-120.

[12] Meena, K. S., Gunsaria, R. K., Meena, K., Kumar, N. and Meena, P. L., The Problem of Hardness in Ground Water of Deoli Tehsil (Tonk District) Rajasthan. Journal ofCurrent Chemical \& Pharmaceutical Sciences, (2011) 2(1): 50-54.

[13] Rolence, C., Machunda, R. L. and Njau, K. N, Potentials of Agric Wastes Activated Carbon for Water Softening. Research Journal in Engineering and AppliedScience 3(3), (2014) 199-207.

[14] S. Mustapha, M.M. Ndamitso, U.M., Mohammed, N.O., Adeosun, and M. Idris,Study on Activated from Melon (Citrulluslanatus) Husk as Natural Adsorbent for Removal of Hardness in Water. Advances in Analytical Chemistry (2016) 6(1): 1-9.

[15] Werkneh, A.A., Abay, A.K., Senbeta, A.M. Removal of water hardness causing constituents usingalkali modified sugarcane bagasse and coffee husk at Jigjiga city, Ethiopia: A comparative study.International Journal of Environmental Monitoring and Analysis (2015), 3(1): 7-16.

[16] Ye, H., Zhang, L., Zhang, B., Wu, G., Du, D., Adsorptive removal of $\mathrm{Cu}$ (II) from aqueous 
Jurnal Teknik Kimia USU, Vol. 5, No. 3 (September 2016)

solution using modified rice husk, International Journal of Engineering Research and Applications (IJERA), Vol. 2, Issue 2, (2012) pp.855863. 